\title{
Gallbladder Melanoma
}

National Cancer Institute

\section{Source}

National Cancer Institute. Gallbladder Melanoma. NCI Thesaurus. Code C5735.

A melanoma that arises from the gallbladder. 